Pre-publication version of article published on $26^{\text {th }}$ February 2019 as: Duckworth, V. and Tett, L. (2019) Transformative and emancipatory literacy to empower, International Journal of Lifelong Education, pp. 1-13 (on-line) DOI: 10.1080/02601370.2019.1574923

\title{
Transformative and emancipatory literacy to empower
}

\author{
Professor Vicky Duckworth, Edge Hill University, UK (vicky.duckworth@edgehill.ac.uk) \\ Professor Lyn Tett, Huddersfield University, UK (I.tett@hud.ac.uk)
}

\begin{abstract}
This paper draws on sociological and critical educational frames, particularly Bourdieu's concept of symbolic violence, in order to contest the dominant model of literacy education that is driven by the premise of a 'knowledge economy'. Instead it foregrounds the political, social, and economic factors that marginalise learners. Data from two projects: an ethnographic study in a Further Education (FE) College in England and a study of community-based literacy programmes in Scotland, are probed to show how literacy classes can offer spaces to challenge symbolic violence and facilitate learners to reclaim identities of success. These changes are illustrated from the learners' views of the contrasts between their experiences of school education and literacy programmes that use transformative and emancipatory approaches. Our research demonstrates how critical education can open up spaces for a more equitable approach based on the co-production of knowledge. It is argued that making changes to policy and practice could inform and shape the literacy curriculum and its pedagogy if adult literacy can disentangle itself from instrumental approaches driven by neoliberal fusion and instead create critical space for contextualised and emancipatory learning.
\end{abstract}

Key words: Adult literacy, critical education, symbolic violence, emancipatory learning, Further Education 
Pre-publication version of article published on $26^{\text {th }}$ February 2019 as: Duckworth, V. and Tett, L. (2019) Transformative and emancipatory literacy to empower, International Journal of Lifelong Education, pp. 1-13 (on-line) DOI: 10.1080/02601370.2019.1574923

\section{Introduction}

The field of adult literacy and basic education has undergone dramatic changes in recent years both nationally and internationally with the advent of a focus on functionality that is based on a human capital framework that positions literacy as a field of knowledge that leads to the economic development of both the individual and society. This drive seeks to connect educational systems to neo-liberal economic development strategies where education is valued only through its contributions to productivity. This leads to programmes that prioritise the labour market, accreditation, and competency-based assessment. For example, the OECD $(2012 ; 2013)$ is focused on the measurement of literacy according to adult 'competencies' and skills. Therefore, as an ideological consequence, decisions about what we ought to be teaching and learning and what ought to be in our curricula, are framed in the context of the overall economic benefit to the entire society. When framed by such human capital discourses, at the level of the individual, literacy becomes reductive (Black \& Yasukawa, 2012); it manifests as a technology for stratifying human beings as embodied labour power and a way of quantifying potential 'productivity'. This framing, through the sorting and delimitation of individuals, can also impact on the productivity and wealth of the communities and societies in which they live (Duckworth and Smith, 2018). For the individual, this model leads to what Gee, Hull, and Lankshear (1996) refer to as 'creating new social identities or new kinds of people' where such identities are inextricably linked to how literacy is acquired and constituted (p. xiii). We argue that this 'economisation' of literacy serves to depoliticise it at the local and individual level and that misrecognition (Bourdieu, \& Passeron, 1977, p. 72) is built into the educational field and the resulting system so that symbolic violence is unexposed and this results in the perpetuation of the cycle of inequality in learners' lives.

In this paper we draw on interviews with learners from research conducted by the authors in England and Scotland to explore the part played by literacy education in relation to its impact on symbolic culture and violence (Bourdieu, 2001) as an embodied identity. We ask two research questions: 1) how do symbolic culture and structure feed into each other to reproduce education and social inequality in learners' lives? 2) Do the learners in our studies recognise the discourses that shape them and if so does this impact on their lives? First, however, we outline our theoretical approaches.

\section{Theoretical approaches}

\section{a) Social approaches to Literacy}

Dominant models of delivering literacies have a strong utilitarian function, selecting and distributing literacy in different ways to different social groups and reproducing class inequalities that fail to address issues of power relations in learners' lives. Critiquing the autonomous model, Hildyard and Olson (1978) contend that the traditional/cognitive model of literacy 'legitimises the extraordinary efforts and resources that go into compulsory schooling' (p. 4). This narrowing of literacy toward a purely functional model is, however, heavily contested. Indeed, in addition to the seminal contribution of Street (1984) on the autonomous and ideological models of literacy, recent theorizations have focused upon the social nature of literacy (Duckworth, 2014; Tett, 2016). 
Pre-publication version of article published on $26^{\text {th }}$ February 2019 as: Duckworth, V. and Tett, L. (2019) Transformative and emancipatory literacy to empower, International Journal of Lifelong Education, pp. 1-13 (on-line) DOI: 10.1080/02601370.2019.1574923

A means to challenge this instrumental approach to curriculum design, which offers a generic 'one size fits all' approach, is to move towards a model based on a social approach to programme design and implentation. Social approaches to literacy are sometimes grouped together under the remit of the New Literacy Studies (NLS) (Barton and Hamilton 1998; Street 1984). This multifaceted view of the nature of literacy challenges the dominance of the autonomous model, and recognises how literacy practices vary from one cultural and historical context to another. In the private domain of home and public domain of formal education, literacy practices, identities and discourse are produced by power and ideology so that literacy is shaped differently in different contexts. As such literacy is not just a technical or neutral skill, it provides a social view that is expanded by treating literacy as not only a social practice but also as a multimodal form of communication.

Educational theorists have challenged prescriptive approaches to curriculum design that do not take into account the history or background and needs of learners (see Giroux 1997; Shor 1992; Duckworth, 2014; Duckworth \& Smith, 2017). These prescriptive curricula ignore the political, social, and economic factors that have marginalised learners and the communities they live in. It is from this position that the critical model moves towards the learner as the co-producer of knowledge. In doing so it shifts away from teacher-directed, top-down, commonly imposed and standardised curricula and assessments that prescribe the same for all learners, regardless of their ability, values, ethnicity, history, their community requirements or their specific contexts. Instead it takes an egalitarian approach, whereby there is a sharing of power between the teacher and the student in learning, the curriculum, its contents and methods. Freire $(1996$, p. 82) proposed to do this via 'culture circles'. A 'culture circle' is a discussion group in which educators and learners use codifications to engage in a dialectic for consciousness raising, liberation, empowerment and transformation. Education for liberation provides a forum open to the empowerment of learners, teachers, and the community, while also providing opportunities for the development of those skills and competencies without which empowerment would be impossible. Such emancipatory practices encourage autonomy and critical thinking, opening up spaces where learners and communities can ask questions, analyse and subsequently work through effective and meaningful strategies to enhance their situation (Duckworth, 2013). Rather than being pawns of the system they then have the opportunity to be actors of their future and active members of their communities.

NLS offers a socially situated model which, like the Freirian 'culture circle', challenges dominant models of literacy, for example replacing the economically driven model associated with workforce training, productivity and the notion of dominant literacies with a socio-cultural model which includes vernacular literacies. It recognises that literacy practices are formed in a number of contexts and domains, for example the private domain of home and the public domain of schooling. In their book, Local Literacies, Barton and Hamilton (1998) explore the many literacy activities people are involved in across the different domains of their life. A key aspect of their findings is that people have 'ruling passions' (Barton and Hamilton, 1998, p. 78) which can be a key into where, why and what literacy practices mattered to them. In this paper we show how a tutor's knowledge of learners' 'ruling passions' can offer a means to recognise and celebrate the learners' practices. Whether the practice is: drawing, words, poetry or photographs like the 'Culture Circles', this approach draws on the literacies from the learners' lives. We also show how these artefacts can be a way to develop a dialogue leading to an 
Pre-publication version of article published on $26^{\text {th }}$ February 2019 as: Duckworth, V. and Tett, L. (2019) Transformative and emancipatory literacy to empower, International Journal of Lifelong Education, pp. 1-13 (on-line) DOI: 10.1080/02601370.2019.1574923

analysis of the concrete reality represented by the learners and facilitating them to address inequalities in their lives.

\section{b) Bourdieu's concepts of capital, field, habitus and symbolic power}

Bourdieu's concepts of capital, field, habitus and symbolic power are used in this paper to contextualise and problematize literacy, or indeed to question what it means to be literate. Literacy is not neutral, rather it is bound into notions of power and powerlessness so:

'language is not simply an instrument of communication: it provides, together with a richer or poorer vocabulary, a more or less complex system of categories, so the capacity to decipher and manipulate complex structures, whether logical or aesthetic, descends partly on the language transmitted in the family' (Bourdieu \& Passeron, 1977, p. 73).

Moreover, Bourdieu (in Bourdieu \& Wacquant, 1992, pp. 241-243) argues that access to legitimate language, in this case literacy, is not equal and that linguistic competence is monopolised by some. In relation to the some, habitus recognises that people are born into different circumstances (for example, into wealth and poverty) and the ways in which different types and amounts of capital shape the learners' lives. Bourdieu (1977) argues that the combination of economic, social, cultural and symbolic capital constitutes a habitus. Different classes, he argues, have different habitus and therefore different perceptions, aspirations, dispositions, tastes and concepts of cultural values etc. Habitus is about social training. Bourdieu refers to habitus as 'a societal imperative which has become a second nature and has been developed into motor schemata and physical automatism' (Bourdieu 1993: 239). This is demonstrated in everyday human behaviour such as 'blowing of the nose' (ibid.), gait and attitudes. On a symbolic level it is visible in, for example, the way a person dresses or their hairstyle. It is not, however, a matter of behaviour being homogenous in terms of notions of distinction and what is valued and what is not. Institutions of education continue to be a 'conservatising' (ibid. p. 240) force, within which teachers bring to the classroom the dominant cultural values and symbolic power related to their legitimate authority. The fields entered and travelled through value or not the symbolic power of literacy. With this in mind, it is important to recognise how literacy in the UK school curriculum has increasingly been used as a key tool in the regime of testing and assessment that ranks schools and children in terms of 'performance' (MacBeath 2015: 14 -15). In England this has resulted in approximately one third of 16 year olds being labelled as having 'failed' (Dorling, 2013: 39). So access to the discourses and discursive practices of literacy is differentially distributed and valued. For those learners who enter the literacy classroom with a competence in the dominant discursive practices or forms of capital, access to literacy is made more easily. Within this context, language background is a form of capital that can be converted into a flow of dominant capital, for example academic credentials of qualifications, that leads to professional employment and the economic and symbolic capitals this flow brings in the form of distinction.

It is important then to recognise that what resources are valued reflects the priorities of the dominant factions in a given field (Grenfell, 2007) and so inequality is reinforced by the primacy afforded the particular forms of capital held by this group. However, its arbitrary nature is veiled because these are seen to be naturally arising and selfevidently superior characteristics and behaviours (Bourdieu \& Passeron, 1977). Bourdieu locates the education system as the most important player in the unequal 
Pre-publication version of article published on $26^{\text {th }}$ February 2019 as: Duckworth, V. and Tett, L. (2019) Transformative and emancipatory literacy to empower, International Journal of Lifelong Education, pp. 1-13 (on-line) DOI: 10.1080/02601370.2019.1574923

distribution of cultural and linguistic capital. This is manifested through its curriculum (see for example: Walkerdine et al. 2001; Skeggs 1997; Luttrell 1997; Horsman 1999; Duckworth \& Smith, 2018) which legitimises the imposition of the "cultural arbitrary", put plainly, the values and meanings of the dominant culture. This veiling results in symbolic violence, which Bourdieu (2001) has described as 'a gentle violence, imperceptible and invisible even to its victims, exerted through the most part by the purely symbolic channels of communication and cognition (more precisely, misrecognition), recognition, or even feeling' (p.1). Thus this type of violence is a symbolic mode of domination that includes labelling and stigma that results in those that are dominated failing to recognize the structures that manipulate them. Instead they internalise the 'blame' and 'guilt' of failing to acquire the dominant modes of literacy for themselves. Symbolic violence also makes it easier, as Scott (2012 p. 533) points out, to shift the emphasis away from the economic relationship that creates unequal opportunity and instead focus the discourse on the individualising values of personal diligence and a strong work ethic. The result of this is that a 'discourse of deficit' (Tett, Hamilton \& Crowther, 2012) is internalised by learners.

A number of critics (e.g. Collins 2009; Watkins, 2017) have argued that Bourdieu focuses too much on determinism and not enough on human agency. Our position is that there are also enabling dimensions of power (Foucault 1990, 1991) so there is space for individuals to play an active role in constructing meaning through their interactions with the discourses they encounter. All interactions position participants in particular ways in relation to the manifestations of power that act on and through them which means that symbolic violence can be resisted and shifted by critical literacies' approaches to education and curriculum design. This framework thus allows us to focus on how such approaches to literacy can be implemented to shape transformative opportunities in the development of literacy programmes and the teaching of literacy. Critical and emancipatory approaches offer a lens to see inside the world of others, through for example, sharing poetry and storytelling; or engaging in collective social action, creating what Duckworth and Smith (2017) describe as a wholeness or confidence that is not a façade or a mask. It comes from a deep understanding of the self as subject: our sense of who we are in society. Therefore, we position the development of literacy programmes and classes as offering resistance against the symbolic violence of an instrumental curriculum and in doing so challenge deficit approaches through supporting learners to be agentic, achieve their goals of a better future for themselves, and indeed, for the society in which they live.

\section{The Research}

In this paper, we draw on data from two projects: an ethnographic study carried out in a Further Education (FE) College in England and a study of community-based literacy projects in Scotland. The English study drew its participants from learners in a Further Education college located in a Northern former mill town with a wide ethnically diverse mix. The general area is populated by minorities, low-income earners and others who are generally classified as under-privileged. The learner cohort was made up of sixteen learners aged between eighteen and late fifties who were enrolled on either a discrete part-time literacy class which run in the day and evening (Duckworth, 2014). The motivations for the learners joining the classes were varied and ranged from wanting to improve their job prospects to hoping to develop confidence. Indeed, confidence was a big issue and something all the group referred to as an important goal. The lessons aimed to create a critical space where the experience of the learners who do not fit with 
Pre-publication version of article published on $26^{\text {th }}$ February 2019 as: Duckworth, V. and Tett, L. (2019) Transformative and emancipatory literacy to empower, International Journal of Lifelong Education, pp. 1-13 (on-line) DOI: 10.1080/02601370.2019.1574923

dominant ideologies are given voice and validated leading to the development of more meaningful knowledge. Subsequently, this knowledge aims to expand on and create concepts that are generated from the lived experience of the group rather than thrust upon it, resulting in explanatory power in the public and private domains of their lives.

The Scottish study was of community-based literacy programs where twenty-seven learners based in five organizations were interviewed near the beginning and towards the end of their programs. The organizations were located in urban areas in the central belt of Scotland, where social and economic deprivation was most concentrated, and the learners comprised those who had experienced precarity due to homelessness and/or addiction issues, those who were living in poverty and working towards employability goals and those for whom attaining their learning goals was problematic due to learning or mental health difficulties. They comprised a 'Health and Literacy' project for people with physical or mental health difficulties, a support project for homeless adults and recovering drug users, a course for women that had experienced violence, a family literacy course in a disadvantaged community and a programme for people with learning difficulties or disabilities. All the organisations were selected because they followed a curriculum that was negotiated with learners and built on their knowledge. Near the beginning of their programmes learners were asked to talk about: their individual life histories, including key life events and their imagined futures. The interviews at the end of the programs asked learners to talk about the overall impact of the programs as well as their imagined futures so that individual changes between the two interviews could be analyzed.

Both projects interviewed learners using an autobiographical approach so that, as Wedin (2008, p. 762) argues, it was possible to examine the 'perspectives and life conditions of the target groups [and] take local, everyday practices into consideration'. Learners were asked to talk about: their individual life histories, including key life events; the influence of key support/learning organizations on their lives; the circumstances in which they were currently situated; and their imagined futures. It is acknowledged that any autobiographical recounting is a construction rather than an objective, complete history (Gluck and Patai 1991) and is a story whose telling is shaped by many factors, especially by the relationship between the teller and the listener. The recounting of the learners' histories was thus likely to be subject to purposeful and unplanned omissions; however, in spite of these challenges, the story each participant shared provided insights into how their previous experiences had influenced their current views of their learning and indeed shaped their trajectories into and out of education.

Thematic analysis (Braun and Clarke 2006) was drawn upon to identify, analyse and report patterns within the interview data so they were first sorted chronologically to construct linear learning histories. Working from the histories, emergent analytic topics became evident. Next, the data were coded by these themes. In the English study in the typing up of the memos and sharing the insights with the group further insights were established. Theoretical sampling repeatedly involved the further gathering and analysis of data, driven by the emerging patterns. Data that tested, contradicted, corroborated or extended on the categories was also used to refine the emergent themes. Great emphasis was placed on attention to the research group's own accounts of social and psychological events and of their associated local phenomenal and social worlds. In the Scottish study a secondary analysis was completed and independently checked by two researchers. The categories that emerged from this process were the impact of early 
Pre-publication version of article published on $26^{\text {th }}$ February 2019 as: Duckworth, V. and Tett, L. (2019) Transformative and emancipatory literacy to empower, International Journal of Lifelong Education, pp. 1-13 (on-line) DOI: 10.1080/02601370.2019.1574923

school experiences and later difficulties, how experiences of marginalization had affected learners' willingness to engage in literacy programmes and the effect of participation in learning on their identities.

In the rest of the paper we examine critical literacy as a tool for empowerment in and out of the classroom but we begin by outlining the ways in which the learners' earlier experiences of schooling and symbolic violence impacted on their habitus and in doing so perceptions of their identities.

\section{Experience of schooling and symbolic violence}

A constraint for the learners in our research was the feelings of shame that resulted from the symbolic and physical violence the interviewees had experienced from their teachers and peers in compulsory education. The impact of being bullied was significant in the accounts of the participants in the study and resulted in them being marginalised, feeling isolated and alone. They did not have the dominant social or cultural capital to recognise the power relations that serve to privilege those already in the most dominant field positions (Bourdieu, 1992).

One learner, Tracy, reported:

'I remember once standing outside the dinner hall and one of the girls who regularly bullied me, pushed in front of me and said, "Bastards to the back of the line!" I was so humiliated. I spent most of the next four years pegging off, even though I loved learning and school; I just hated the daily taunts about my looks, my hair and my clothes. The experience left me with little confidence, very low self-esteem and self-hatred'.

Another, John, said 'I was bullied so much at school... I didn't take anything in - there were so many sniggering remarks and I basically used to sit and doodle all day'.

Learners were not passive in their experiences and there was strong evidence that they rejected schooling because of a number of constraining factors. These included: being labelled negatively by their school teachers for being poor; struggling with their school work; having a habitus that was out of sync with the school; and for some being raised in homes that were neglectful of their welfare. Peter's experience exemplifies this vividly:

'My Mum left when I was six weeks old and my dad brought me up but he remarried and I wasn't treated well by my stepmother. I don't remember any happy times, birthdays, family times, holidays or even ordinary cuddles. There was just no discipline there so I ended up going off the rails and I started sniffing glue and drinking so I rarely went to Secondary school.

Although qualifications are the dominant capital in education, this 'weight' was not placed upon them. Instead they experienced the 'weight' of symbolic violence and labels related to failure. However, they found spaces to escape and to 'get out of school' as soon as possible. Part of this struggle included asserting their agency by not going to school so that they could reject the negative stigma they experienced (Goffman 1970). 
Pre-publication version of article published on $26^{\text {th }}$ February 2019 as: Duckworth, V. and Tett, L. (2019) Transformative and emancipatory literacy to empower, International Journal of Lifelong Education, pp. 1-13 (on-line) DOI: 10.1080/02601370.2019.1574923

\section{Rachel describes how:}

'I didn't go back to school cos the bullying happened every day. I didn't want to go and it held me back. I knew I was bright, l'd always been told that, but the bullying made me feel bad".

Many learners described how the pedagogy of school failed to engage them. The symbolic violence experienced being a 'power which manages to impose meanings and to impose them as legitimate by concealing the power relations which are basis of its force' (Collins and Makowsky, 1993, p. 259). For example, Mary was very slow at reading but did not feel that the teachers noticed and she thought that they were:

'...more interested in the bright ones, the ones that could get on...They sort of just left me to one side... I tried to do my best, but I just felt that because I wasn't bright and I wasn't brainy that people just didn't want to know'.

Others described how school was boring and held no interest, compared with a more hands on approach which they might have been able to relate to. When their habitus encountered the field of schooling it created ambivalence, insecurity and uncertainty (Reay, 2005) as they were deemed to lack the right qualities. Many were unable to focus on the lessons and found the didactic approach which did not recognise their practical skills but recognized instead their lack of economic capital did not work. Their habitus was not in sync with the middle-class discourse of schooling. For example, Tracy commented on the 'education shoes' that were issued free to those who had uniform vouchers from the welfare service and how they contributed to the bullying she experienced. The shoes and what they signified (poor and needing welfare) equated to Tracy being a 'shabby failure'. She failed to conform to the dominant habitus of respectability, because her shoes were not bought by earned economic capital. She had become discouraged by the fact she was labelled and pathologised by teachers and peers for lacking the qualities deemed necessary to succeed in schooling and be popular with peers at school.

These learners' experiences show how the prevalence of competition in schools, through high-stakes testing and league tables of performance together with the inequitable distribution of resources, helps maintain the advantage of learners from privileged backgrounds, especially in the context of the winner taking all. It also shows how they internalised the discourse of deficit and the symbolic violence to which they were subject (Bourdieu, 2001).

In our research, holistic and critical participation in literacy was explored in the context of narratives and discourses. We explored creative literacy as a language system which can be energised as a conductor for learners to share their world picture and words with other members of the group, make meanings out of their life and circumstances and shape their identity, whilst also developing literacy skills. It also facilitated the learners to use cultural acts as a lens to see beyond themselves and to learn to develop insights and understandings of people whose culture, ethnicity, gender and sexual orientation is different than their own. The classrooms operated to engage in the cultural capital (texts and images) generated by the learners and their community and mobilised them as creative literacy resources. 
Pre-publication version of article published on $26^{\text {th }}$ February 2019 as: Duckworth, V. and Tett, L. (2019) Transformative and emancipatory literacy to empower, International Journal of Lifelong Education, pp. 1-13 (on-line) DOI: 10.1080/02601370.2019.1574923

Poetry and art was used as a way to engage learners in a critical dialogue. For example, a former literacy learner but now a teacher at the college, Linda, composed a poem in class when there were race riots in the local area. Teaching to an ethnically diverse class, where there continued to be tensions around race and gender, the poem was used as a foil and discussion piece and for consciousness-raising. This facilitated the group to share and challenge their assumptions about identity and racism. It also opened up a space to use poetry as a means for emotional expression. Until she saw the poem, Carol thought reading and writing poetry was for those with 'qualifications and ... good jobs'. She described how she connected with the poem but felt scared of exploring the possibilities of her own experiences by putting pen to paper as writing poetry was 'not for someone like me'. Carol was experiencing symbolic violence and the:

'Universal adopted strategy for effectively denouncing the temptation to demean oneself is to naturalise difference, to turn it into second nature through inculcation and incorporation in the form of the habitus' (Bourdieu, 1992, p. 122).

However, on reading Linda's poem she seemed totally amazed that people who lived on the same streets as her had written such 'magic'. She said: If they can do it, who are just like me, so can I. Her position in the field changed. She soaked up the lessons, even asking for poetry. Inspired by, rather than running from, words she began to embrace language as something she had the right to use. She described how on shaping sentences it really helped her to: deal with those lousy feelings that have crammed my life too often like doubt, failure and fear. The positive aspects of transformative learning experience were also added to by the impact of seeing the world in new critical ways. Discovering she had a flair for writing poetry helped her realise: I used to think everyone was better, now I know we're all the same, equal.

Taking control of language empowered Carol and the belief she could use words to express herself. She turned the symbolic violence she had initially experienced into symbolic power. Carol's confidence developed together with her self-esteem. Writing poetry was very much linked with her view of self. She gained self-esteem from writing about her thoughts and feelings:

When I read out my poems I feel like the class is really listening to me. That makes me proud [because] it's being able to share some painful memories rather than hiding them away. I've got the guts to do it now; I'm not frightened; like I used to be.

Although many learners recounted experiences that had led them to explicitly reject education, various life events and the problems with which they were struggling had led them back into learning. For some the often, traumatic experience of addictions had caused them to return to education in order to take up new ways of living. Their literacy programmes had caused them to re-evaluate their previous understandings of themselves as people without knowledge and instead helped them to see that they had experience that could help others. So their experience of homelessness was seen as an asset that demonstrated their ability to analyse their own problems within the context of adverse societal conditions that they had learned to overcome. This meant that they saw their literacy learning as a resource that would help them to achieve the changes in their lives to which they aspired. For example, Kathy said: 
Pre-publication version of article published on $26^{\text {th }}$ February 2019 as: Duckworth, V. and Tett, L. (2019) Transformative and emancipatory literacy to empower, International Journal of Lifelong Education, pp. 1-13 (on-line) DOI: 10.1080/02601370.2019.1574923

It motivates me that the tutors are working so hard to help me. I've already been able to write an email and had a good result from it. I feel it's the first time anyone's reacted to anything l've written.

Learners were encouraged to use their personal experiences as positive resources rather than being seen as lacking knowledge. For example, in one of the Scottish projects parents were asked to discuss the role that they played in their children's education through their everyday talking and listening activities in the home so that they could see their contribution was as important as those of the teachers. This meant that they were able to imagine different scenarios that foregrounded what they were good at rather than dwelling on their failures and thus they were able to create a new imaginary trajectory and position in the world. Most learners had worked through many of their past negative experiences and gained the competences that enabled them to see themselves as potentially successful learners. Tutors had operated from a strengths approach to literacy tuition that drew on learners' experiences as a positive resource and thus challenged the symbolic violence caused by the arbitrary nature of school knowledge. Learners' gained positive identities not only because of changing experiences but also because of the dialogue that took place around those experiences in ways that promoted social awareness and a critique of existing inequities. For example, building on learners' passions around football led to critiques of how football supporters were depicted in the media and lively discussions of how that might be challenged and changed.

\section{Discussion}

The classroom is a space that is dynamic, changing and shaped by the people who inhabit it. Critical literacy is an empowering tool in this 'dynamic space' for transformation where learners can explore and 'read the world' (Freire, 1996) by sharing their narratives in creative multi-modal ways. In the context of narratives and discourses, it exposes how the use of creative literacy in the learners' lives was a means to share their words and images with other members of the group, make meanings out of their circumstances and shape their identities, whilst also developing literacy skills. Using multimodal approaches which include poetry and images, can be a move towards reflection and transformation. Shifting the habitus systems of dispositions that generate perceptions, expectations, beliefs and actions in a particular context, in this case creativity, can arise from sharing creativity and encouraging learners to think beyond a competence-based approach to literacy. The confidence that arises for creativity can help the learners in other fields. For example, Tracy described how: I feel more confident in myself and being a mother when I paint. It's something the social services can't take from me. The creativity opened a space for transformation because:

'writing has a power quite different to talking or thinking. (...) The act of writing creates an object to which the writer can relate tangibly, visually and aurally. (...) And this tangibility lasts over time, to be re-experienced in different frames of mind, different stages of life' (Bolton, 1999, p. 213 - 14 cited in O'Rourke, 2005. p. 244).

The creativity also flowed into the family; Tracy sharing her creative outlet with her daughter Mia who subsequently began to write poetry about her emotionally 'upsetting' relationship with her father. She describes below how writing poetry for the first time helped her come to terms with the pain she had felt.

Resp: Them awful feelings that made me feel sick got a bit better. 
Pre-publication version of article published on $26^{\text {th }}$ February 2019 as: Duckworth, V. and Tett, L. (2019) Transformative and emancipatory literacy to empower, International Journal of Lifelong Education, pp. 1-13 (on-line) DOI: 10.1080/02601370.2019.1574923

Int: How's that?

Resp: It's like when I write I can talk things through on the page that l'd normally keep to myself. It helped me get rid of really hurtful stuff. Do you know what I mean?

For Bourdieu cultural acts, such as creative writing, are a form of cultural capital. Bourdieu sought to 'historicise culture as a field, with the aim of deconstructing the ideologies interpolated within it, which may be deemed to align culture with 'nature' and so naturalise the difference. This again directly impacts on the reproduction and reinforcement of the classes, in that it functions in fields of aesthetics that are linked. As identified by Bourdieu 'It must never be forgotten that the working-class aesthetic is a dominated aesthetic which is constantly obliged to define itself in terms of dominated aesthetics' (Bourdieu, 1984, p. 41). Our research has exposed how, in breaking with the dominant ideology which positions creative writing and poetry in the realm of distinction, bringing it into the field of a basic skills class has impacted on the learners' identities and lives. The creativity opened a space for transformation. This transformation saw a shift in Carol and other leaners' habitus because the classes offered a critical space for them to explore their creativity and their literacy practices. The hierarchy of taste and style which are embedded in culture are useful when considering Carol, Tracy and Mia's attitude towards creativity. Poetry and art were classed for 'people not like us'. Bourdieu (1984) suggested the ways in which apparently distinctive and individualised consumption and leisure practices tend to betray their class origins. In order to challenge this hegemony of distinction, which serves to oppress the working classes, judgment of taste must hold open a future that goes beyond the culture of the dominant or dominated.

Bourdieu's theoretical model has provided a framework through which to understand the constraints that learners experience in their daily life and how the veiling of dominant discourses results in the internalising of 'failure to learn'. We have also drawn on Foucault $(1990,1991)$ in considering the enabling dimensions of power that allow notions of agency whilst also recognising the structural inequalities that impact on this. We also show, however, that the relevance of class and gender on the learners' trajectories has continued importance in the era of individualising modernity (Beck 1994). Further to this, the concept of different types of capital and how they are accrued and valued used in this paper are important in facilitating a more detailed analysis of different relations of power which can remain hidden and implicit in concepts such as 'individualism', 'choice' and 'mobility'. The non-recognition of such injurious practices maintains the illusion that problems are individual and not shaped by the social contexts in which we live and have our being.

The learners' narratives have exposed the contradiction, complexities and ambivalences they experience in their daily lives and how they try to make sense of them from their structural positioning as basic skills learners in a society based on inequality of opportunity and choice. Dialogic engagement with learners facilitated the sharing of cultural capital through eliciting their 'funds of knowledge' (González, et al, 2005) and validating them through the sharing of stories. Capitalising on learners' histories and socially situated knowledge was an important aspect of developing and implementing a culturally responsive pedagogy. Personal literacies were driven by the creative aspects and led to situations of transformation whereby there was no longer acceptance of the rules of the game and the goals proposed by the dominant class. So, while some 
Pre-publication version of article published on $26^{\text {th }}$ February 2019 as: Duckworth, V. and Tett, L. (2019) Transformative and emancipatory literacy to empower, International Journal of Lifelong Education, pp. 1-13 (on-line) DOI: 10.1080/02601370.2019.1574923

curricula seek to preserve the status quo, others, like the examples from our research, strive to challenge and transform existing hierarchies. Offering a space both in the classroom and the community for the learners to share their narratives allowed the sharing of obstacles and solutions to overcome them. In this capacity, the narratives are themselves a capital which can be pulled on by others to inspire and offer strategies to move forward. For example, Tracy's story offered strategies for dealing with bullying, whilst Joanne's related to her learning journey and overcoming obstacles, such as being poor, being in an abusive relationship and the power of education to transform her and her children's lives for the better. When Joanne arrived at the literacy class in the college, she struggled to read and write and sat at the back of the class. Avoiding eye contact she neither spoke to her tutor nor the other learners. However, after Joanne joined the literacy class, she began to spend more time with her tutor and classmates. This provided the opportunity to speak to her in detail about the barriers she had faced and her hopes and talk about her aspirations for the future. The journey was not however easy for Joanne who described how her former husband would carry out physical and psychological abuse throughout the course and when she started nursing. She felt she could not turn to her family because of the pain they had caused her and spoke of how:

'He tried to stop me getting anywhere'. Int: How did he do that?

Resp: Where do I start. He'd tell me he's pick the kids up from school and then I'd get a call at uni telling me they were waiting. It made me look like a crap mother but I was doing it all for them. He just told lies and strung me along.

Int: Did anything help you get through all that?

Resp: Having the literacy class really helped me. I looked forward to the nights. It also made a difference knowing I could call the tutor and chat.

The stories also offer accounts that others can draw on to resist structural inequalities and a lack of flow of capitals across the domains of their lives. This validated their experience and deconstructed the old knowledge, where they blamed themselves for being 'thick' and 'stupid' because they struggled in literacies and instead substituted it with the construction of new, shared knowledge where they were able to see the inequalities and violence in their lives this had stemmed from. Critical literacy offered a space for dialogue and the reimaging of the exploration of 'hope' and new possibilities. For Joanne this hope become cemented in her trajectory leading to her becoming a qualified registered nurse and:

My life has been turned around, I sometimes have to pinch myself that I have a job that gives me fulfilment, a decent wage and a life away from the violence that hit me and the kids hard. Learning to read and write in a class where my voice mattered, ... really gave me back the me who could take control, who could make something of my life and not be a mat for beating. Yeah, I am who I want to be now and don't hide away in shame. And I make sure that I share my experiences, that's important you see. 
Pre-publication version of article published on $26^{\text {th }}$ February 2019 as: Duckworth, V. and Tett, L. (2019) Transformative and emancipatory literacy to empower, International Journal of Lifelong Education, pp. 1-13 (on-line) DOI: 10.1080/02601370.2019.1574923

However, despite attempts to rewrite their own history and to mould a different life trajectory through education, the learners were still bound by the significance of class through both cultural process and the reproduction of position through their capitals or lack of them. This process was complex and robust; they were constrained and empowered depending on time and space, and not necessarily in a linear way. For example, for Joanne, college was the mediating site for her transition from working as a sewing machinist to nursing. Joanne describes how she viewed the student nurses:

They all seem cleverer than me somehow. Sometimes I wonder if it's worth putting myself through the stress [but what keeps me going is] I suppose it's' having you and the others in the research group to talk to. It's daft I know having this self-doubt but sometimes I can't help it. I can't believe I actually got here sometimes I just get a nagging that I'll lose it.

The gap between the habitus and the needs of the fields, created a space for reflection, this reflection led Joanne to try to develop her linguistic capital so she felt more confident and comfortable in the field of health.

The learners' narratives illuminate how the habitus is always in process, in that socialisation into different classed and gendered identities is never complete. The learners took agency and shaped their habitus so it was not incongruent with the field. We would suggest, however, that this process was not simplistic. Indeed, for the learners in our studies there was often a contradiction between how they appeared to the public gaze and how they appeared to their internal gaze. This incongruence caused great anxiety when appearances were in conflict with inner feelings of emotional ambivalence and feeling like an 'outsider' and 'unworthy'. Consider Joanne's perceived lack of linguistic capital and how this positioned her in the field of nursing. The habitus had a durability that even the acquisitions of capitals could not make congruent within the field of nursing. The learners' narratives offered us insight into their habitus that reflected what was seen as well as unseen. It is these narratives which allowed a deep awareness of the impact of past experiences of symbolic violence on the learners' changing positions across the field they inhabited and travelled.

\section{Conclusion}

In this paper we have shown how symbolic culture and structure feed into each other to reproduce education and social inequality in the learners' lives. Educational institutions are not neutral in the value placed on the accumulation of capital and its transmission so learners who attend adult literacy classes have often had to overcome significant barriers to gain the confidence and courage to return to learning. The learners' nonadherence to academic norms required for distinction as recognised by the dominant paradigm, led to them taking the blame and as such internalizing negative emotions. This hid the symbolic power schools have in the continual reproduction of social hierarchy. These emotions arose from the negative labels that were attached because they struggled at school. Furthermore, for many adult learners, negative labelling in the compulsory education system due to teacher expectation and the resulting self-fulfilling prophesy (see Ball 1981) may lead to learners being labelled as 'slow', thus leaving them with low self-esteem and confidence.

However, the learners in our studies have recognised the discourses that shape them and the impact on their lives. When they arrived at Further Education or Community 
Pre-publication version of article published on $26^{\text {th }}$ February 2019 as: Duckworth, V. and Tett, L. (2019) Transformative and emancipatory literacy to empower, International Journal of Lifelong Education, pp. 1-13 (on-line) DOI: 10.1080/02601370.2019.1574923

settings, they were given the space to explore their life and learning narratives and make sense of events that have held them back. As we have shown, this can remove the negativity, resulting in academic progress and personal fulfilment especially when tutors engage with learners in egalitarian ways. Even when learners have been in vulnerable situations, facing domestic violence or other social or emotional difficulties, adult literacy education can often be a critical space to support and empower them to take agency, no matter what their trajectory so far. The tutors in our studies were able to create safe learning environments, based on respect, where learners could flourish and reach their potential.

There are implications for both policy and practice from our findings. Violence and trauma, including the fall-out of austerity, has an impact on all literacy learners, their families and communities in many ways which include mental and physical well-being, economic and social capitals or lack of capitals. It offers an indicator of the relationship of the learners to the state and the social values which underpin it. Changes to policy and practice could inform and shape the literacy curriculum and pedagogy; a central driver being adult education/literacy dis-entangling itself from neoliberal fusion and creating critical space for contextualised and critical literacy. Critical literacy and indeed education can open up spaces for a more equitable approach where a level playing field is established for those from disadvantaged backgrounds. We need to recognise and address the historical and contemporary disparities that exist in the structural inequalities between the learners and their lives e.g. class, gender and ethnicity. A way to address this is for educators and society to recognise and value the cultural dimensions the learners bring with them and work through dialogic engagement with these to create a curriculum that is meaningful to their lives and the communities in which they live. This requires a conceptualisation of the theoretical and methodological issues involved in understanding and representing the literacy curriculum based on respect, within which learners can flourish and reach their potential (Duckworth, 2013, Duckworth \& Smith, 2018). 


\section{References}

Ball, S.J. (1981). Beachside Comprehensive: A case study of secondary schooling. Cambridge: Cambridge University Press.

Barton, D. and Hamilton, M. (1998). Local Literacies: Reading and Writing in One Community, London: Routledge

Beck, U. (1994). The reinvention of politics', in U. Beck, A. Giddens \& S. Lash (Eds.), Reflexive modernisation: politics, tradition and aesthetics in the modern social order (pp. 1 - 55). Cambridge: Polity Press.

Black, S. and Yasukawa, K. (2012). Shared delivery: integrating ELT in Australian vocational education, ELT Journal, 66 (3) pp. 347-355

Bourdieu, P. (1977). Outline of a theory of Practice, Cambridge: Cambridge University Press

Bourdieu, P. (1984). Distinction: A Social Critique of the Judgement of Taste, London: Routledge \& Kegan Paul.

Bourdieu, P. (1992). Thinking about limits. Theory, Culture and Society, 9(1), 37-49.

Bourdieu, P. (1993). Sociology in question. London: Sage.

Bourdieu, P. (2001). Masculine Domination. Translated by Richard Nice. Stanford, CT: Stanford University Press.

Bourdieu, P. and Passeron, J. (1977). Reproduction in Education, Society and Culture. London: Sage.

Bourdieu, P. and Wacquant, L. (1992), An Invitation to Reflexive Sociology, Chicago: University of Chicago Press.

Braun, V. and V. Clarke. (2006). Using Thematic Analysis in Psychology. Qualitative Research in Psychology 3 (2), 77-101.

Collins, J. (2009). "Social Reproduction in Classrooms and Schools." Annual Review of Anthropology, 38: 33-48.

Collins, R and Makowsky, M (1993). The discovery of society. New York: McGraw Hill.

Dorling, D. (2013). The Population of the UK, 2nd Ed. London: Sage. 
Pre-publication version of article published on $26^{\text {th }}$ February 2019 as: Duckworth, V. and Tett, L. (2019) Transformative and emancipatory literacy to empower, International Journal of Lifelong Education, pp. 1-13 (on-line) DOI: 10.1080/02601370.2019.1574923

Duckworth, V. (2013). Learning Trajectories, Violence and Empowerment amongst Adult Basic Skills Learners. London: Routledge.

Duckworth, V. (2014). Literacy and Transformation. In V. Duckworth \& G. Ade-Ojo (Eds.), Landscapes of Specific Literacies in Contemporary Society: Exploring a social model of literacy (pp. 27-46). London: Routledge.

Duckworth, V., \& Smith, R. (2017). FE: Transforming lives and communities, Interim report. UCU. Retrieved from: http://transforminglives.web.ucu.org.uk/2017/01/19/furthereducation-in-england-transforming-lives-andcommunities/

Duckworth, V., \& Smith, R. (2018). Breaking the triple lock: Further education and transformative teaching and learning. Education + Training, 60(6), 529-543.

doi:10.1108/ET-05-2018-0111

Foucault, M. (1990). The History of Sexuality Volume 1: An Introduction. London: Penguin.

Foucault, M. (1991). Discipline and Punish: The Birth of the Prison. London:

Penguin.

Freire, P. (1996). Pedagogy of the Oppressed. London: Penguin.

Gee, J. P., Hull, G. \& Lankshear, C. (1996). The New Work Order: Behind the Language of the New Capitalism. Sydney and Boulder, CO.: Allen \& Unwin and Westview Press.

Giroux, H. (1997). Pedagogy and the politics of hope: Theory, culture, and schooling. Boulder. CO: Westview.

Gluck, S. B., and D. Patai, Eds. (1991). Women's Words: The Feminist Practice of Oral History. New York: Routledge.

Goffman, E. (1970). Stigma. Harmondsworth: Penguin.

González, N., Moll, L., \& Amanti, C. (2005). Funds of knowledge: Theorizing practices in households, communities and classrooms. Mahwah, NJ: Erlbaum.

Grenfell, M. (2007). Pierre Bourdieu: Education and training. London: Continuum International.

Hildyard, A. \& Olson, D. (1978). 'Literacy and the specialisation of language' Unpublished manuscript, Ontario Institute for studies in education. (Referred to in Street, 1984).

Horsman, J. (1999). Too Scared to Learn: Women, Violence and Education. Toronto: McGilligan Books.

Luttrell, W. (1997). School-smart and Mother-wise: Working-class Women's Identity and Schooling. New York: Routledge.

MacBeath, J. (2015). How good is our classroom? Teachers taking back responsibility. 
Pre-publication version of article published on $26^{\text {th }}$ February 2019 as: Duckworth, V. and Tett, L. (2019) Transformative and emancipatory literacy to empower, International Journal of Lifelong Education, pp. 1-13 (on-line) DOI: 10.1080/02601370.2019.1574923

In Reclaiming schools: The evidence and arguments (pp. 14-15). Retrieved from https://www.teachers.org.uk/files/reclaimingschools-essays-9963.pdf

OECD. (2012). "Better Skills, Better Lives: A Strategic Approach to Skills Policies." Paris: OECD.

O'Rourke, R. (2005). Creative Writing: Education, culture and community. Leicester: Niace.

Reay, D. (2005). Beyond Consciousness? The Psychic Landscape of Class? Sociology. $395,911-928$.

Scott, Brigitte C. (2012). Caring Teachers and Symbolic Violence: Engaging the Productive Struggle in Practice and Research. Educational Studies, 48(6), 530-549.

Shor, I. (1992). Empowering Education: Critical Teaching for Social Change, London: University of Chicago Press.

Skeggs, B. (1997/2002). Formations of Class and Gender, 2nd edn, 2002. London: Sage.

Street, B. (1984). Literacy in Theory and Practice. Cambridge: Cambridge University Press.

Tett, L. (2016). Learning, literacy and identity: 'I don't think I'm a failure any more'. British Journal of Sociology of Education, 37(3), 427-444. doi:10.1080/01425692.2014.939265

Tett, L., Hamilton, M., \& Crowther, J. (Eds.). (2012) More Powerful Literacies. Leicester: NIACE.

Walkerdine, V., Lucey, H., and Melody, J. (2001). Growing up Girl: Psychosocial Explorations of Gender and Class. London: Palgrave.

Watkins M. (2018). Little room for capacitation: rethinking Bourdieu on pedagogy as symbolic violence. British Journal of Sociology of Education, 39(1), 47-60.

Wedin, A. (2008). Literacy and Power: The Cases of Tanzania and Rwanda. International Journal of Educational Development, 28(6), 754-763. 